\title{
Effect of Carica papaya Leaf Juice on Blood Cell Count of Busulfan-Induced Chronic Bone Marrow Aplasia in Mice
}

\author{
${ }^{1}$ Sofia Yasmeen Abbasi, ${ }^{2}$ Rukhsana Kausar, ${ }^{1}$ Hira Naz, ${ }^{3}$ Sadia Chiragh \\ ${ }^{1}$ Department of Pharmacology, Fatima Jinnah Medical University, Lahore \\ ${ }^{2}$ Department of Pharmacology, Services Institute of Medical Sciences, Lahore \\ ${ }^{3}$ Department of Pharmacology, Al-Aleem Medical College, Lahore
}

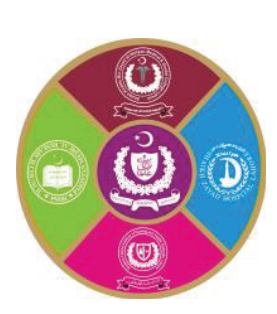

\begin{abstract}
Introduction: Aplastic anemia is a syndrome of bone marrow failure comprising of peripheral pancytopenia and marrow hypoplasia. Recently, research has shown papaya leaf juice to increase blood cells counts.

Aims \& Objectives: This research was planned to investigate the effect of papaya leaf juice on blood cell counts in busulfan induced myelosuppressed mice.

Place and duration of study: Post Graduate Medical Institute, Lahore from September 2015 to December 2015.

Material \&Methods: This animal experimental study comprised of 36 adult healthy Swiss albino mice weighing 30-35 $\mathrm{g}$, divided randomly into three equal groups. Busulfan was given orally $(14 \mathrm{mg} / \mathrm{kg})$ to induce myelosuppression to busulfan group and Carica papaya + busulfan group on 8 occasions over a period of 23 days. Carica papaya leaf juice $(10 \mathrm{ml} / \mathrm{kg})$ was given to the Carica papaya+ busulfan group daily for 23 days to observe its role in preventing myelosuppression. Normal group was given distilled water in an equivalent amount. One day after the final dose of busulfan and Carica papaya, the animals were sampled for blood cell counts. Data was analyzed using SPSS version 20. A p-value $<0.05$ and below was considered as significant.

Results: The Carica papaya leaf juice not only prevented significant fall in hemoglobin $(10.86 \pm 1.455 \mathrm{~g} / \mathrm{dl}), \mathrm{RBC}(9.54$ $\left.\pm 0.954 \times 10^{6} / \mathrm{mm}^{3}\right)$ and platelet count $\left(958.92 \pm 176.22 \times 10^{3} / \mathrm{mm}^{3}\right) \mathrm{vs}(9.70 \pm 0.904,11.24 \pm 0.952 \mathrm{~g} / \mathrm{dl})$, RBC count $\left(6.5025 \pm 1.43,10.43 \pm 0.234 \times 10^{6} / \mathrm{mm}^{3}\right)$ and platelet count $\left(627.83 \pm 151.63,3881.08 \pm 83.13 \times 10^{3} / \mathrm{mm}^{3}\right)$ in busulfan group but also kept them close to normal range. Total leukocyte count in C.papaya treated group improved significantly to $8116.67 \pm 1540.85 / \mathrm{mm}^{3}$ vs $\left(4516.67 \pm 789.51,6666.67 \pm 798.10 / \mathrm{mm}^{3}\right)$ busulfan treated and normal groups respectively. Conclusion: The Carica papaya leaf juice possesses significant myeloprotective activity. It may be a good candidate for prevention of chemotherapy induced pancytopenia.
\end{abstract}

ABSTRACT

Key words: Aplastic anemia, Chemotherapy, Myeloprotective, Carica papaya

\section{INTRODUCTION}

B one marrow failure is a disease syndrome characterized by a drastic decline in marrow's functional ability to produce mature blood cells. ${ }^{1} \mathrm{~A}$ paradigm of bone marrow failure is a disease called aplastic anaemia, in which patients have essentially empty bone marrow accompanied by severe anaemia, neutropenia and thrombocytopenia. ${ }^{2}$ The costly and hazardous ways of treatment of aplastic anaemia such as; bone marrow transplantation, immunosuppression and blood transfusion, have led the scientists to research on alternative methods for treatment of aplastic anaemia which are easily applicable and patient friendly. ${ }^{3}$

Papaya, botanical name Carica papaya, a tropical tree with multiple benefits, is available throughout the year. ${ }^{4}$ The leaves of Carica papaya are richly supplied with many healthy elements like papain, chymopapain, tocopherol, cystatin, ascorbic acid, flavonoids and glucosinolates ${ }^{5,6}$ that enhance the gross anti-oxidant activity in blood and decrease the lipid peroxidation level. ${ }^{7}$ Many fruitful researches on role of papaya leaf extract/juice in boosting up the platelet count, white blood cell (WBC) count and erythrocyte (RBC) count have been carried out. ${ }^{8,9,10}$ These all studies are performed on normal animals, dengue patients or reversible models of myelosuppression. The current study was planned to explore the effect of Carica papaya leaf juice on prevention of irreversible myelosuppression induced by busulfan. This study might help in treatment of chronic bone marrow conditions like aplastic anaemia.

\section{MATERIAL AND METHODS}

After Institutional Review Board approval (No: 0043-S-2014 dated 18.10.2014), the study was carried 
out at Postgraduate Medical Institute (PGMI), Lahore from September to December 2015. In this animal experimental study, adult Swiss albino healthy mice of either sex weighing 30-35 grams were obtained from University of Veterinary and Animal Sciences, Lahore and kept in Animal House of PGMI maintaining hygienic conditions. The room temperature was maintained at $25 \pm 2^{\circ} \mathrm{C}$ and mice were provided water and rat chow ad libitum.

\section{Carica papaya leaf juice preparation:}

The leaves of Carica papaya plant, obtained from home garden, were washed and dried thoroughly, veins and petioles parts were separated and only the leaf blades were pestled and then squeezed by applying moderate pressure using a muslin cloth so that approximately $10 \mathrm{ml}$ juice was obtained from approximately $25 \mathrm{~g}$ leaf blades (yield $=40 \% \mathrm{~V} / \mathrm{W}$ ). Fresh juice was prepared daily as required. ${ }^{11}$

\section{Induction of Chronic Bone Marrow Aplasia:}

For the induction of bone marrow aplasia $14 \mathrm{mg} / \mathrm{kg}$ dose of busulfan (GlaxoSmithKline) was given orally to each mouse as single morning dose on days $0,3,8,11,15,18,21 \& 23$ (eight occasions) over a period of 23 days to group B (busulfan) and group C (Carica papaya + busulfan group). ${ }^{12}$

\section{Experimental Design:}

With $90 \%$ power of study and 5\% level significance, the sample size of 12 per group was calculated. ${ }^{11}$ The mice were randomly designated to Normal group, Busulfan Group and Carica papaya + Busulfan Group. To Busulfan Group and Carica papaya + Busulfan Group, busulfan was given as described above, to induce bone marrow aplasia after measuring body weight to adjust the dose. Distilled water $10 \mathrm{ml} / \mathrm{kg}$ was given daily orally for 23 days consecutively to Normal group and Busulfan group, while Carica papaya leaf juice 10 $\mathrm{ml} / \mathrm{kg}^{11}$ was administered to Carica papaya + busulfan group, daily orally as a single morning dose for 23 consecutive days.

Body weight was measured at baseline and on days of busulfan administration and dose was adjusted accordingly.

After 24 hours of final dose of busulfan and Carica papaya leaf juice, the animals were sampled for blood examination. Blood was taken by cardiac puncture using ketamine anesthesia by $3 \mathrm{ml}$ syringe of 23-gauge needle, following thoracotomy incision. Blood was collected in vacutainers (lilactop), anti coagulated with EDTA and analyzed for RBC, hemoglobin $(\mathrm{Hb})$, total leukocyte count (TLC) and platelet count with a hematology analyzer (Sysmex KX-21). Differential leukocyte count (DLC) was analyzed manually on Giemsastained slide under oil immersion lens. Absolute count of each type was calculated using DLC \% and TLC.

\section{Statistical analysis:}

Data was expressed as mean \pm standard deviation after processing by SPSS 20. Graph Pad Prism was used for graphical representation. One way ANOVA followed by post hoc Tukey's test was applied for comparison between the groups. Paired sample two tailed t-test was used to see difference between times in body weight. The $p$-value $<0.05$ was considered as significant, $<0.01$ highly significant and $<0.001$ very highly significant.

\section{RESULTS}

\section{Body Weight:}

Although body weight of mice was measured on all days of busulfan administration, but for statistical analysis body weight on day 0,11 , and 23 was taken. Comparison of body weight (Mean $\left.{ }_{-} \mathrm{SD}\right)$ by ANOVA revealed that body weight was similar on day 0 but significant differences were present on day 11 and 23. Paired t-test values showed that body weights of Normal group and Carica papaya+ busulfan group did not change significantly over time, whereas the Busulfan group showed a significant reduction in body weight (Table-1).

\begin{tabular}{|c|c|c|c|c|c|c|}
\hline \multirow{2}{*}{ Group } & \multirow{2}{*}{\begin{tabular}{|c} 
Day0 \\
Mean \pm \\
SD
\end{tabular}} & \multirow{2}{*}{\begin{tabular}{|c} 
Day 11 \\
Mean \pm \\
SD
\end{tabular}} & \multirow{2}{*}{$\begin{array}{c}\text { Day } 23 \\
\text { Mean } \pm \\
\text { SD }\end{array}$} & \multicolumn{3}{|c|}{$\begin{array}{c}\text { pvalue } \\
\text { paired t- test }\end{array}$} \\
\hline & & & & \begin{tabular}{|c|} 
Day0 \\
vs. 11
\end{tabular} & \begin{tabular}{|c} 
Day 11 \\
vs. 23
\end{tabular} & $\begin{array}{l}\text { Day0 } \\
\text { vs. } 23\end{array}$ \\
\hline Normal & $\begin{array}{c}30.11 \pm \\
1.19\end{array}$ & $\begin{array}{c}29.97 \pm \\
1.08\end{array}$ & $\begin{array}{c}30.50 \pm \\
1.16\end{array}$ & 0.45 & 0.086 & 0.096 \\
\hline Busulfan & $\begin{array}{l}30.75 \\
\pm 1.48 \\
\end{array}$ & \begin{tabular}{|c|}
$29.41 \pm$ \\
1.24 \\
\end{tabular} & $\begin{array}{c}28.58 \pm \\
0.99\end{array}$ & $<0.001$ & \begin{tabular}{l|l}
1 & 0.044
\end{tabular} & $<0.001$ \\
\hline $\begin{array}{c}\text { C.papaya }+ \\
\text { busulfan }\end{array}$ & $\begin{array}{c}29.50 \pm \\
0.67 \\
\end{array}$ & \begin{tabular}{|c|}
$29.91 \pm$ \\
0.79 \\
\end{tabular} & $\begin{array}{c}30.00 \pm \\
0.17 \\
\end{array}$ & 0.054 & 0.723 & 0.053 \\
\hline $\begin{array}{c}\text { pvalue } \\
\text { ANOVA }\end{array}$ & 1.000 & 0.003 & $<0.001$ & & & \\
\hline
\end{tabular}

Table-1: Effect of Carica papaya leaf juice on body weight $(\mathrm{g})$ of busulfan induced myelosuppressedmice $(\mathrm{n}=12)$

\section{Hemoglobin Level:}

The comparison of means \pm SDof $\mathrm{Hb}$ level of all groups by ANOVA revealed a significant difference between the group means with a $p$ value of 0.006 . Multiple comparison by post Hoc Tukey's test on day 23 revealed that hemoglobin level of Busulfan group was significantly lower than Normal group while the hemoglobin level of Carica papaya+ busulfan group was significantly higher as compared to Busulfan group as shown in Fig-1A. 


\section{RBC Count:}

The comparison of RBC count (mean $\pm \mathrm{SD}$ ) of all groups by ANOVA revealed a significant difference between the group means with a p-value of $<0.001$. Multiple comparisons by post hoc Tukey's test at day 23 revealed that $\mathrm{RBC}$ count of Busulfan group was significantly lower as compared to Normal group, whereas RBC count of Carica papaya + busulfan group was significantly higher as compared to Busulfan group (Fig-1B).

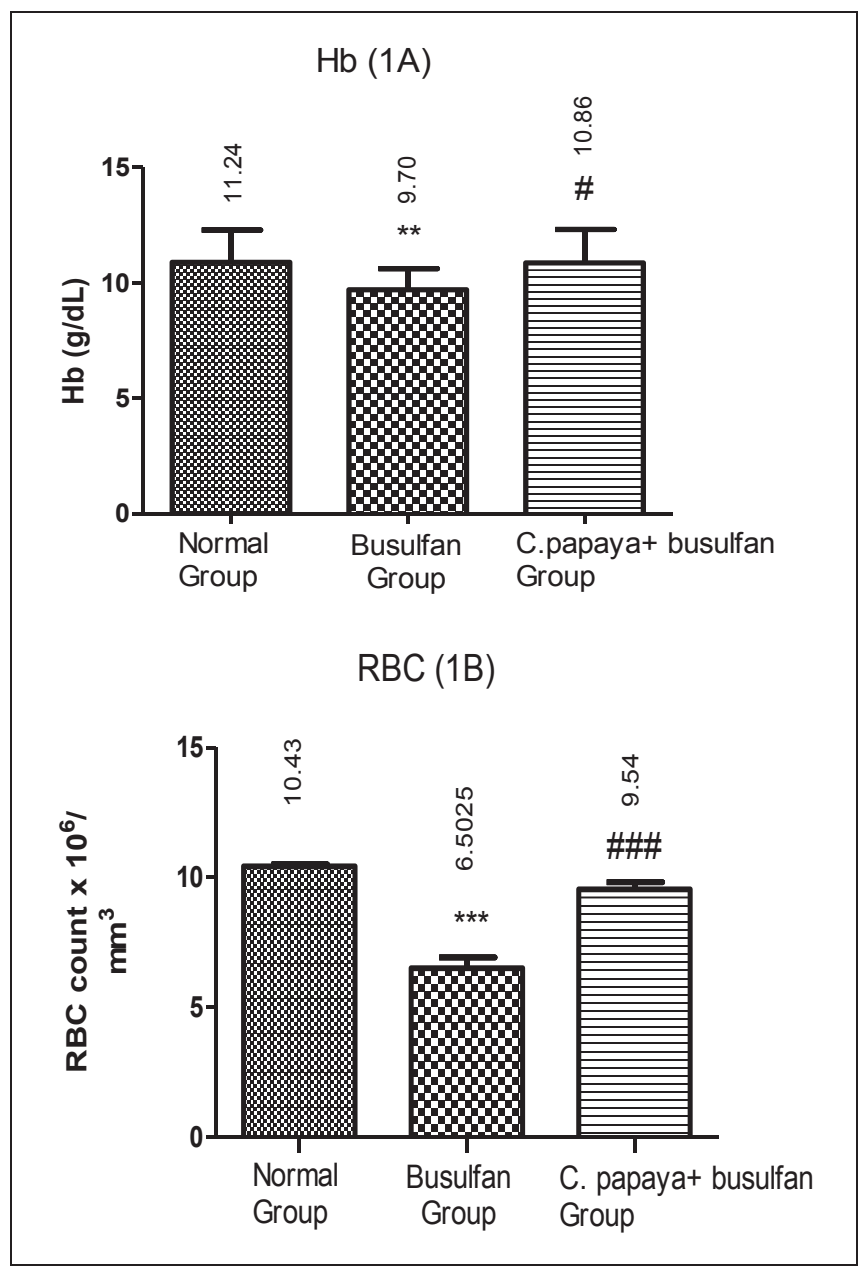

Fig-1A \&1B: Effect of Carica papaya leaf juice on mean $\pm \mathrm{SD}$ of $\mathrm{Hb}(\mathrm{g} / \mathrm{dl})$ levels in busulfan induced myelosuppressed mice (A) $(n=12)$. And RBC count $\times 10^{6} / \mathrm{mm}^{3}$ in busulfan induced myelosuppressedmice (B) $n=12$ ).

$* *$ p-value $\leq 0.01$ vs Normal group

$\# \#$ \#-value $\leq 0.001$ vs Busulfan group

Total Leukocyte Count and Platelet Count:

The TLC was significantly lowered ( $p$-value of $<$ 0.001 ) in Busulfan group as compared to Normal group, whereas it was significantly higher in Carica papaya + busulfan group as compared to Normal group and Busulfan group as shown in Fig-2A.

The platelet count in Busulfan group was significantly lower as compared to Normal group and Carica papaya+ busulfan group, whereas the difference between Normal group and Carica papaya+ Busulfan group was statistically insignificant (Fig-2B).

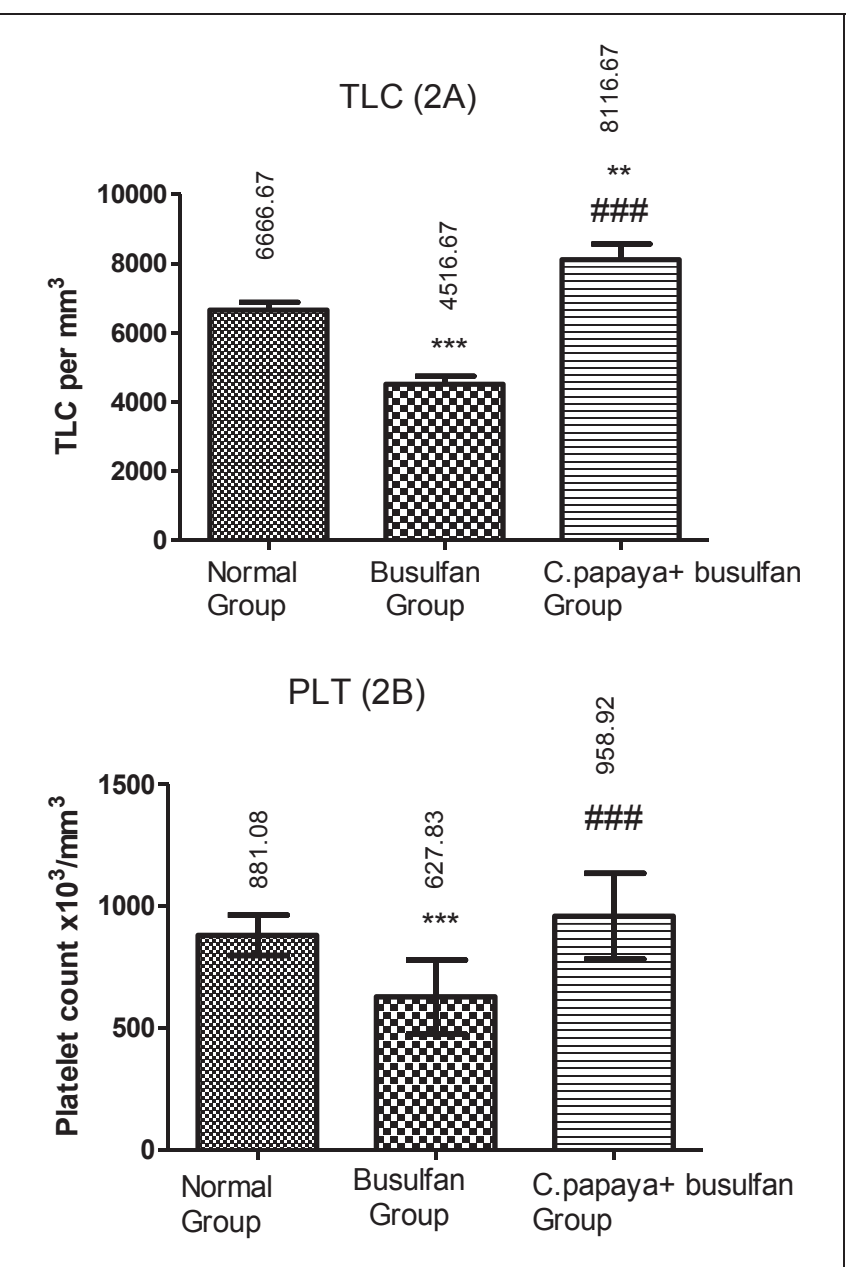

Fig-2A\&2B: Effect of Carica papaya leaf juice on mean $\pm \mathrm{SD}$ of TLC count $/ \mathrm{mm}^{3}$ in busulfan induced myelosuppressed mice (A) $(n=12)$. and platelet count $\times 10^{3} / \mathrm{mm}^{3}$ (B) in busulfan induced myelosuppressed mice $(\mathrm{B})(\mathrm{n}=12)$.

$* * p$-value $\leq 0.01$ vs Normal group

$\# \#$ \#-value $\leq 0.001$ vs Busulfan group

\section{Differential Leukocyte Count:}

The polymorph neutrophils, lymphocyte, monocyte and eosinophil absolute counts (Mean \pm SD) of all the groups is given in fig- 3 . The comparison of means of all the groups by ANOVA revealed a significant difference between the group means of neutrophil count with a p-value of $<0.001$. On multiple comparison, neutrophil count of Busulfan group was significantly lower as compared to Normal group and Carica papaya+ busulfan group. Lymphocyte count in all groups was statistically similar. 


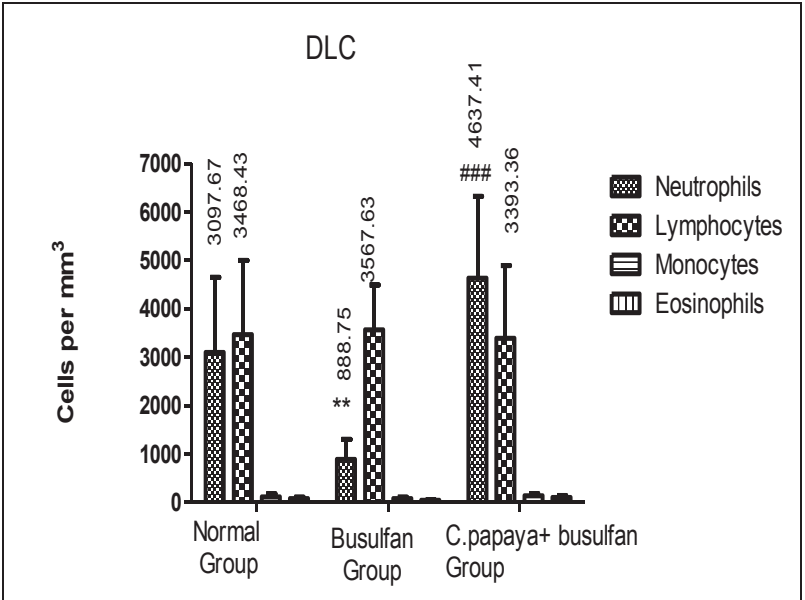

Fig-3: Effect of Carica papaya leaf juice on differential cell count per $\mathrm{mm}^{3}$ (Mean $\pm \mathrm{SD}$ ) in busulfan induced myelosuppressed mice $(\mathrm{n}=12)$

$* *$ p-value $\leq 0.01$ vs Normal group

$\# \#$ \#-value $\leq 0.001$ vs Busulfan group

\section{DISCUSSION}

Aplastic anemia is a bone marrow disorder comprising of peripheral blood pancytopenia and bone marrow hypocellularity. ${ }^{13}$ Although management of severe aplastic anemia has progressed in past four decades because of improvement in hematopoietic stem cell transplantation, immunosuppressive biologics, drugs and medical care; still, management of severe aplastic anemia remains demanding because of disease's natural history and the repercussions of therapy, ${ }^{14}$ necessitating investigation of new compounds.

This study was conducted to observe the effect of Carica papaya leaf juice on blood cell count of busulfan induced myelosuppression in mice with promising results of significant prevention in fall of all blood cell counts. In past years, several agents have been used to induce bone marrow suppression in experimental animals including benzene ${ }^{15}$, busulfan $^{16}$ Carboplatin $^{11}$ and cyclophosphamide. ${ }^{17}$ For this study, busulfan was selected and preferred over other agents because it causes irreversible damage to bone marrow. ${ }^{16}$

Administration of busulfan to mice resulted in significant fall in blood hemoglobin level and RBC, TLC, platelet, and neutrophil counts. Similar results were observed when busulfan was used to induce bone marrow aplasia in Balb-c mice by Wen et al. ${ }^{18}$ In current study administration of Carica papaya leaf juice prevented fall in $\mathrm{RBC}$ count and hemoglobin level, keeping near to that in Normal group. In another study, sodium nitrite induced anemia in mice showed an improvement in erythrocyte count and hemoglobin concentration with Carica papaya leaf juice. ${ }^{19}$ These findings support the results of the present study. Carica papaya leaves contain an appreciable number of alkaloids, saponins, phytate, flavonoid, tannin and glycosides that might have a stimulant effect on red blood cell production. ${ }^{20}$ Carica papaya leaves have a high content of $\mathrm{Fe}$ and vitamin $\mathrm{C}$. Iron plays a role in the formation of hemoglobin and $\mathrm{Vit} \mathrm{C}$ reduces $\mathrm{Fe}^{3+}$ to $\mathrm{Fe}^{2+}$ making it easy to absorb iron which might be a cause of prevention in fall of $\mathrm{Hb}$ in Carica papaya + busulfan group in this study. Vitamin $\mathrm{C}$ is also a powerful anti-oxidant that prevents the free radical damage of bone marrow progenitors, thus responsible for an increase in the hemoglobin levels. ${ }^{21}$

Results of current study showed that the administration of Carica papaya leaf juice along with busulfan prevented a fall in the platelet count keeping it near to normal. Previous studies showed that Carica papaya leaf extract significantly increased the platelet count in cyclophosphamide induced thrombocytopenia in rats after being treated with $400 / 800 \mathrm{mg} / \mathrm{kg}$ daily for 15 days. $^{22}$ It was concluded from a 21day study, on carboplatin induced thrombocytopenia in mice that Carica papaya leaf juice prevented not only a fall in platelet count rather increased the count above baseline $\mathrm{p}<0.001 .{ }^{11}$ This leaf juice has shown promising results by raising platelet count in dengue fever $^{23}$ as well as in chemotherapy induced thrombocytopenia. ${ }^{24}$ The alkaloid components of Carica papaya leaves acting on bone marrow may inhibit the destruction and boost the ability of bone marrow to produce platelets. ${ }^{20}$

In this study, the TLC was significantly higher in the Carica papaya+busulfan group as compared to Busulfan and Normal groups with a p-value of $<$ 0.05 , which indicates that Carica papaya leaf juice not only prevented the fall in TLC but also raised it. An eight-day study was carried out on a dengue patient who was given $25 \mathrm{ml}$ of Carica papaya leaf juice orally twice daily resulting in a rise of WBCs count from 3600 cells/cm to 10,500 cells/cm which favors the current results. ${ }^{23}$ Flavonoid and flavanol constituents of Carica papaya leaves have showed an anabolic effect that could be responsible for the stimulant effect on blood cell production. ${ }^{25}$

In the current study, the absolute differential leukocyte count of neutrophils and lymphocytes was measured. Busulfan group significantly lowered the neutrophil count as compared to the Normal group (p-value $<0.003$ ) which was sustained and raised significantly by the Carica papaya+busulfan group ( $p$-value of $<0.001)$. Moreover, it was found that 
the lymphocytic count in the busulfan and the Caricapapaya+busulfan group remained statistically similar to Normal group. Possible explanation for this shown behavior might be as the busulfan mainly has a role on bone marrow for inducing myelosuppression, mostly affecting B lymphocytes, the overall lymphocyte count remained same as there are also other sources present in body for proliferating lymphocytes like thymus for $\mathrm{T}$ lymphocytes and natural killer cells in blood. ${ }^{26}$

Results of this study favor the hypothesis, which make Carica papaya leaf juice a potential candidate for further research leading to the development of herbal therapeutic agent for preventing myelosuppression. Only basic parameters were evaluated and detailed research to establish mechanism of action was not possible due to limitation of resources. It is especially important to recognize the active ingredients of Carica papaya leaves which can be used as medicine to boost thrombopoiesis, granulopoiesis and erythropoiesis in humans where these cell lineages have been compromised.

\section{CONCLUSION}

It can be concluded from this study that Carica papaya leaf juice can be used to prevent thrombocytopenia, anemia and leukopenia induced by chemotherapy.

Acknowledgement: We are grateful to staff of animal house and Hematology laboratory of PGMI, Lahore for their help.

\section{REFERENCES}

1. Weinzierl EP, Arber DA. The differential diagnosis and bone marrow evaluation of new-onset pancytopenia. Am. J. Clin. Pathol. 2013;139(1):9-29.

2. Gandhi S, Abuarqoub H, Kordasti S, Jiang J, Kulasekararaj A, Mufti G, Marsh JC. Pathology of bone marrow failure syndromes. Diag. Histopathol. 2015; 21(5): 174-80.

3. Bacigalupo A. How I treat acquired aplastic anemia. Blood. 2017;129(11):1428-1436.

4. Vij T, \& Prashar Y. A review on medicinal properties of Carica papaya Linn. Asian. Pac. J. Trop. Dis. 2015; 5(1): 1-6.

5. Singh SP, Kumar S, Mathan SV, Tomar MS, Singh RK, Verma PK, Kumar A, Kumar S, Singh RP, Acharya A. Therapeutic application of Carica papaya leaf extract in the management of human diseases. DARU. J. Pharm. Sci. 2020; 5:1-10.

6. Ugo NJ, Ade AR, Joy AT. Nutrient Composition of Carica Papaya Leaves Extracts. J. Food Nutr. Res. 2019;2(3): 274-282.
7. Maisarah AM, Nurul Amira B, Asmah R, Fauziah O. Antioxidant analysis of different parts of Carica papaya. Int. Food Res. J. 2013;20(3): 1043-1048.

8. Akhtar T, Khan M \& Eva E. Comparative evaluation of platelet augmentation activity of Carica papaya leaf juice and hydrocortisone in thrombocytopenic rats. Bangladesh. J. Physiol. Pharmacol. 2015; 30(2): 32-40.

9. Arollado EC, Pena IG, Dahilig VR. Platelet augmentation activity of selected Philippine plants. I.J.P.P.R. 2013; 3(2): 121-123.

10. Saraf M \& Kavimandan B. Animal trials of Carica papaya leaf extracts for increasing platelet count. Indian. J. Public. Health. Res.\& Dev.2017;8(4):782-7

11. Tahir N, Zaheer Z, Kausar S, \& Chiragh S. Prevention of fall in platelet count by carica papaya leaf juice in carboplatin induced thrombocytopaenia in mice. Biomedica. 2014; 30(1): 21-24.

12. Scheinberg P, Chen J. Aplastic anemia: what have we learned from animal models and from the clinic. SeminHematol.2013; 50 (2):156-164.

13. Wang L, Liu H. Pathogenesis of aplastic anemia. Hematology. 2019; 24(1):559-66.

14. Boddu PC, Kadia TM. Updates on the pathophysiology and treatment of aplastic anemia: a comprehensive review. Expert review of hematology. 2017;10(5):433-448.

15. Elsayed AS. Induction of aplastic anemia in experimental model.Int. j. appl.2016;7(1): 182-195

16. Montecino-Rodriguez E, Dorshkind K. Use of busulfan to condition mice for bone marrow transplantation. STAR protocols. 2020;1(3):100159.

17. Feng L, Huang Q, Huang Z, Li H, Qi X, Wang Y, Liu Z, Liu X, \& Lu L. Optimized animal model of cyclophosphamide-induced bone marrow suppression. B. C. P. T. 2016; 119: 428-435.

18. Wen S, Dooner MS, Papa E, Tatto MD, Pereira M, Cheng $\mathrm{Y}$, et al.Reversal of aplastic anemia by mesenchymal stem cell-derived extracellular vesicles. Blood. 2017; 130 (S 1): 2456.

19. Hamidah A, Anggerini E, \& Nurjanah N. Effect of Carica papaya leaf Juice on hematology of mice (Mus musculus) with anemia. Biosaintifika: Jr. Bio. \& Bio. Educ. 2017; 9(3): 417-422.

20. Oche O, Rosemary A, Ojuwu J, Chidi E, Rebbeca S, \& Vincent U. Chemical constituents and nutrient composition of Carica papaya and vernonia amygdalina leaf extracts. J. O. C. A. M. R. 2017; 2(1): $1-8$.

21. Akbari A, Jelodar G, Nazifi S,Sajedianfard J. An overview of the characteristics and function of vitamin $\mathrm{C}$ in various tissues: relying on its antioxidant function.Zahedan J Res Med Sci. 2016; 18(11):e4037.

22. Patil S, Shetty S, Bhide R, \& Narayanan S. Evaluation of platelet augmentation activity of Carica papaya leaf aqueous extract in rats. J. Pharmacogn. Phytochem. 2013; 1(5): 57-60.

23. Deepak BSR, Girish KJ, \& Lakshmiprasad J. Effect of Papaya leaf juice on platelet and WBC count in 
Dengue fever: A Case Report. J. A. H. M. 2013; 1(3): 44-47.

24. Sundarmurthy DRJ, \& Kuntegowdanahalli L. Effect of Carica papaya leaf extract on platelet count in chemotherapy-induced thrombocytopenic patients: A preliminary study. Natl. J. Physio. Pharm. Pharmacol. 2017; 7(7): 685-692.

25. Tham CS, Chakravarthi S, Haleagrahara N, \& Alwis R. Morphological study of bone marrow to assess the effects of lead acetate on haemopoiesis and aplasia and the ameliorating role of Carica papaya extract. Exp. Ther. Med. 2013; 5: 648-652.

26. Rechavi E, Lev A, Lee YN, Simon AJ, Yinon Y, Lipitz S, Amariglio N, Weisz B, Notarangelo LD, Somech R. Timely and spatially regulated maturation of $\mathrm{B}$ and $\mathrm{T}$ cell repertoire during human fetal development. Sci. Transl.Med. 2015; 7(276):276ra25.

\section{The Authors:}

Dr. Sofia Yasmeen Abbasi

Senior Demonstrator,

Department of Pharmacology,

Fatima Jinnah Medical University, Lahore.
Dr. Rukhsana Kausar

Associate Professor,

Department of Pharmacology,

Services Institute of Medical Sciences, Lahore.

Dr. Hira Naz

Demonstrator,

Department of Pharmacology,

Fatima Jinnah Medical University, Lahore.

Prof. Dr. Sadia Chiragh

Head, Department of Pharmacology,

Al-Aleem Medical College, Lahore.

\section{Corresponding Author:}

Dr. Hira Naz

Demonstrator,

Department of Pharmacology,

Fatima Jinnah Medical University, Lahore.

E-mail: h.naz960@gmail.com 